\title{
Gap junction uncoupling protects the heart against ischemia
}

\author{
Adam E. Saltman, MD, PhD \\ Tunc 0. Aksehirli, BSc ${ }^{\text {a }}$ \\ Virginijus Valiunas, $\mathrm{PhD}^{\mathrm{b}}$ \\ Glenn R. Gaudette, MSME ${ }^{\mathrm{a}}$ \\ Nanristu Matsuyama, MD \\ Peter Brink, PhD ${ }^{\mathrm{b}}$ \\ Irvin B. Krukenkamp, MD ${ }^{a}$
}

From the Division of Cardiothoracic Surgery $^{\mathrm{a}}$ and the Department of Physiology and Biophysics, ${ }^{\mathrm{b}}$ The Institute for Molecular Cardiology, State University of New York at Stony Brook, Stony Brook, NY.

Received for publication Oct 10, 2001; revisions requested Nov 8, 2001; revisions received Feb 8, 2002; accepted for publication Feb 18, 2002.

Address for reprints: Adam E. Saltman, $\mathrm{MD}, \mathrm{PhD}$, Division of Cardiothoracic Surgery, State University of New York at Stony Brook, Health Sciences Center T19080, Stony Brook, NY 11794-8191 (Email: adam.saltman@sunysb.edu).

J Thorac Cardiovasc Surg 2002;124:371-6

Copyright (C) 2002 by The American Association for Thoracic Surgery

0022-5223/2002 \$35.00+0 12/1/124239

doi:10.1067/mtc.2002.124239

Background: Many stimuli can successfully protect the heart against ischemia. We investigated whether gap junction uncoupling before ischemia was myoprotective. We also studied the function of the adenosine triphosphate-dependent potassium channel, which has been implicated in the mechanism of pharmacologic preconditioning, with respect to gap junction physiology.

Methods: Twenty-eight rabbit hearts were placed on a Langendorff perfusion apparatus. Five were given a 5-minute infusion of $1 \mathrm{mmol} / \mathrm{L}$ heptanol (a gap junction uncoupler), 5 were given $10 \mu \mathrm{mol} / \mathrm{L}$ 2,3-butanedione monoxime (an electromechanical uncoupler), and 6 were given no drug. The left anterior descending coronary artery was then occluded for 1 hour and reperfused for 2 hours. Six hearts received $10 \mu \mathrm{mol} / \mathrm{L}$ glybenclamide before heptanol to evaluate the role of the adenosine triphosphate-dependent potassium channel. Six hearts underwent ischemic preconditioning with 2 cycles of 5 minutes of global ischemia and reperfusion. Action-potential duration of the ischemic zone, left ventricular developed pressure, and coronary flow were measured continuously. Infarct size was determined at the end of reperfusion.

Results: Heptanol significantly reduced infarct size (from $46 \% \pm 2 \%$ to $22 \% \pm 5 \%$, $P<.01$ ), an effect that was not prevented by glybenclamide. Butanedione monoxime decreased developed pressure but did not significantly reduce infarct size $(46 \% \pm 5 \%$ vs $46 \% \pm 2 \%, P=$ not significant). There were no differences among groups with regard to developed pressure or action-potential duration.

Conclusion: Directly blocking gap junctions preconditions the heart. This protection is not a direct result of a decrease in developed pressure before a prolonged ischemic period nor is it achieved through a mechanism involving the adenosine triphosphatedependent potassium channel.

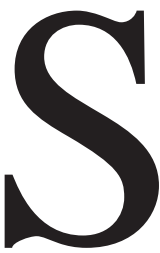

hort episodes of myocardial ischemia stimulate a protective defense mechanism against prolonged ischemia. ${ }^{1}$ This process has been termed ischemic preconditioning (IPC). It has been reported that high levels of arachidonic acid (AA), as well as linoleic and decosahexanoic acids, are released during ischemia. ${ }^{2}$ AA has been shown to uncouple gap junctions. ${ }^{3,4}$ The preconditioning effect of controlled gap junction uncoupling before ischemia, however, is unknown. Therefore we hypothesized that gap junction uncoupling alone confers protection against a prolonged ischemic insult.

In addition to ischemia, however, many other methods have been used to provoke the preconditioning response, such as cardiopulmonary bypass, ${ }^{5} \alpha$-adrenergic ago- 


\begin{tabular}{|c|c|c|c|c|c|c|}
\hline \multirow{3}{*}{ Control } & \multirow[b]{3}{*}{5} & \multirow[b]{3}{*}{$5^{\prime}$} & \multirow[b]{3}{*}{$5^{\prime}$} & \multirow[b]{3}{*}{$5^{\prime}$} & \multirow{2}{*}{$\begin{array}{c}60^{\circ} \\
\text { Regional Ischemia } \\
\end{array}$} & \multirow{2}{*}{$\begin{array}{c}120^{\circ} \\
\text { Reperfusion }\end{array}$} \\
\hline & & & & & & \\
\hline & & & & & $60^{\circ}$ & $120^{\circ}$ \\
\hline \multirow[t]{2}{*}{ IPC } & GI & Rep & $\mathrm{GI}$ & Rep & Regional Ischemia & Reperfusion \\
\hline & & & $5^{\prime}$ & $5^{\prime}$ & $60^{\circ}$ & $120^{\circ}$ \\
\hline \multirow[t]{2}{*}{ Heptanol } & & & Hep & Rep & Regional Ischemia & Reperfusion \\
\hline & & & 5 & $5^{\prime}$ & $60^{\circ}$ & $120^{\circ}$ \\
\hline \multirow[t]{2}{*}{ BDM } & & & BDM & Rep & Regional Ischemia & Reperfusion \\
\hline & & $5^{\prime}$ & $5^{\prime}$ & $5^{\prime}$ & $60^{\circ}$ & $120^{\circ}$ \\
\hline lamide \& Heptanol & & Gly & Hep & Rep & Regional Ischemia & Reperfusion \\
\hline
\end{tabular}

Figure 1. Schematic diagram of experimental protocols. Drugs were infused before 60 minutes of regional ischemia and 120 minutes of reperfusion. GI, Global ischemia; Rep, drug-free reperfusion; Hep, $1 \mathrm{mmol} / \mathrm{L}$ heptanol; Gly, 10 $\mu \mathrm{mol} / \mathrm{L}$ glybenclamide.

nists, ${ }^{6,7}$ protein kinase $\mathrm{C}$ activators, ${ }^{6,8}$ adenosine, ${ }^{6,8}$ and adenosine triphosphate (ATP)-sensitive potassium channel openers.9,10 Because the ATP-dependent potassium $\left(\mathrm{K}^{+}{ }_{\text {ATP }}\right)$ channels appear to play a major role in preconditioning, ${ }^{11-13}$ we attempted to dissect out their role in preconditioning by using the $\mathrm{K}^{+}{ }_{\text {ATP }}$ channel blocker glybenclamide.

\section{Material and Methods}

Animals received humane care in compliance with the "Principles of Laboratory Animal Care" formulated by the National Society for Medical Research and the "Guide for the Care and Use of Laboratory Animals" prepared by the Institute of Laboratory Animal Resources, National Research Council, and published by the National Academy Press, revised 1996.

Adult male New Zealand rabbits, weighing between 2.8 and 3.0 $\mathrm{kg}$, were anesthetized with $30 \mathrm{mg} / \mathrm{kg}$ sodium pentobarbital and anticoagulated with 1000 units of sodium heparin through an ear vein. Once the corneal reflex was abolished, the rabbits were placed in the supine position, and the chest was entered through a bilateral thoracotomy. The heart was rapidly excised and placed in an iced bath of Krebs-Henseleit solution $\left(\mathrm{Na}^{+}, 135 \mathrm{mmol} / \mathrm{L} ; \mathrm{K}^{+}\right.$, $4.7 \mathrm{mmol} / \mathrm{L} ; \mathrm{Ca}^{++}, 1.7 \mathrm{mmol} / \mathrm{L} ; \mathrm{P} 04^{--}, 1.1 \mathrm{mmol} / \mathrm{L} ; \mathrm{Mg}, 1.2$ $\mathrm{mmol} / \mathrm{L}$; $\mathrm{HC}^{-}{ }^{-}, 25 \mathrm{mmol} / \mathrm{L}$; glucose, $11.5 \mathrm{mmol} / \mathrm{L}$; pyruvate, 4.9 $\mathrm{mmol} / \mathrm{L}$; and fumarate, $5.4 \mathrm{mmol} / \mathrm{L}$ ). The aorta was instrumented with a stainless-steel $8 \mathrm{~F}$ cannula, and the heart was suspended from the cannula within a heated glass chamber (Radnotti, Monrovia, Calif). The aorta was then perfused with oxygenated $(95 \%$ $\mathrm{O}_{2} / 5 \% \mathrm{CO}_{2}$ ) Krebs-Henseleit solution at $37^{\circ} \mathrm{C}$ and $75-\mathrm{mm}-\mathrm{Hg}$ root pressure.

The hearts were permitted to equilibrate for 20 minutes. During that period, both atria were excised, and a small balloon was placed through the mitral valve into the left ventricle. Balloon pressure was monitored continuously (Millar Corporation, Houston, Tex). The initial end-diastolic pressure was set to 5 to $10 \mathrm{~mm}$ $\mathrm{Hg}$ by means of water inflation, and the volume was maintained constant throughout the experiment. The hearts were paced at 150 beats/min with an asynchronous pacemaker (Medtronic, Minneapolis, Minn). Monophasic action potentials were recorded from the left ventricular epicardium within the distribution of the left anterior descending coronary artery (LAD) by using an $8 \mathrm{~F}$ spring- loaded probe (EP Technologies, Mountainview, Calif). Coronary flow was measured directly by means of timed collection.

The overall experimental protocol is shown in Figure 1. Six hearts served as controls without treatment before LAD ischemia. Six hearts underwent global IPC before LAD ischemia. This was accomplished with 2 episodes of 5 minutes of complete aortic inflow occlusion followed by 5 minutes of reperfusion. Five hearts received a 5-minute infusion of $1 \mathrm{mmol} / \mathrm{L}$ heptanol, a gap junction uncoupling agent, followed by a 5-minute washout period before LAD ischemia. To determine whether $\mathrm{K}^{+}$ATP channels are involved in the myocardial response to gap junction uncoupling, 6 hearts received a 5 -minute infusion of $10 \mu \mathrm{mol} / \mathrm{L}$ glybenclamide before heptanol infusion. Because gap junction uncoupling resulted in decreased developed pressure during treatment, 5 hearts were treated with $10 \mathrm{mmol} / \mathrm{L} \mathrm{2,3-butanedione} \mathrm{monoxime} \mathrm{(BDM;}$ an electromechanical uncoupler). ${ }^{14}$

Regional ischemia was then induced by broadly encircling the LAD close to its origin with a 3-0 silk suture and snaring with a tourniquet. At the end of 1 hour of ischemia, reperfusion was achieved by releasing the tourniquet and briefly massaging the LAD with a moistened cotton swab. After reperfusion, the hearts were removed from the perfusion apparatus, the suture was resnared, and $2 \mathrm{~mL}$ of monostryl blue was infused through the aortic cannula to stain tissue not at risk. The right ventricle was excised, and the left ventricle was sectioned horizontally at 1- to 2-mm intervals. The slices were then incubated in $1 \%$ triphenyl tetrazolium chloride for 15 minutes to stain viable tissue pink. Tissue remaining unstained was therefore infarcted. Both sides of each section were scanned (Sigma Scan; Jandel Scientific, San Rafael, Calif) into an IBM-compatible computer (Dell Corp, Austin, Tex). Infarct size was expressed as a percentage of the area at risk:

Infarct size $=$
$\sum_{\text {slices }} \frac{\left[\frac{\text { Infarct area }(\text { side } A)+\text { Infarct area }(\text { side } B)}{\text { Total area }(\text { side } A)+\text { Total area }(\text { side } B)} \times \text { Slice weight }\right]}{\left[\frac{\text { Risk area }(\text { side } A)+\text { Risk area }(\text { side } B)}{\text { Total area }(\text { side } A)+\text { Total area }(\text { side } B)} \times \text { Slice weight }\right.}$

$\times 100 \%$

Comparisons among groups were made with analysis of variance for repeated measures (Systat v5.02; Systat, Inc, Evanston, 




Changes in Peak Developed Pressure During the Pretreatment Phase

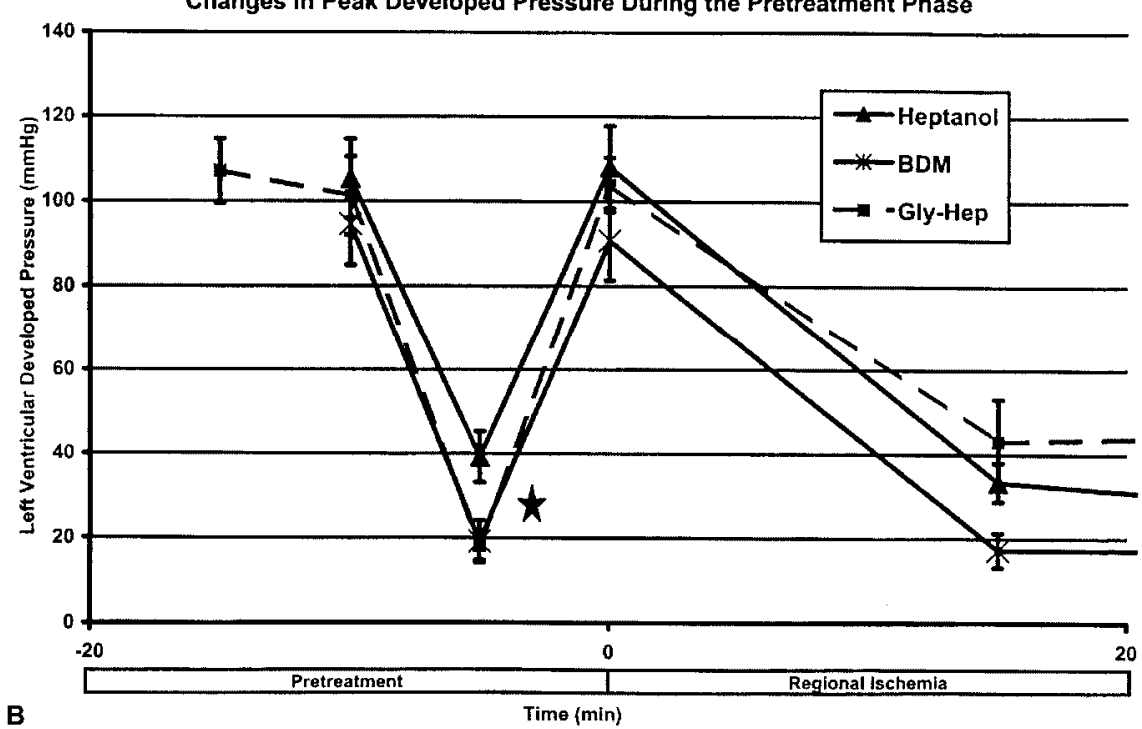

Figure 2. A, Changes in developed pressure during pretreatment, regional ischemia, and reperfusion phases. Data are given as mean \pm SEM. There were no significant differences between groups. $B$, Detail of changes in developed pressure during the pretreatment phase only. Data are given as mean \pm SEM. Open triangles indicate $P$ values of less than .05 comparing all groups between time $-\mathbf{5}$ minutes and time -10 minutes. There were no significant differences between groups. Gly-Hep, $10 \mu \mathrm{mol} / \mathrm{L}$ glybenclamide plus $1 \mathrm{mmol} / \mathrm{L}$ heptanol.

Ill). As indicated, between-group multiple comparisons were made with the Tukey post-hoc test.

\section{Results}

Developed Pressure

End-systolic pressure and end-diastolic pressure were measured directly from the balloon pressure tracings, and peak developed pressure (PDP) was calculated as the difference between end-systolic pressure and end-diastolic pressure for each beat. During the pretreatment phase, there were sig- nificant changes (Figure 2, A). Heptanol, heptanol with glybenclamide, and BDM all reduced PDP to a similar degree during pretreatment (Figure 2, B). During regional ischemia, PDP was significantly reduced in all groups. During reperfusion, PDP returned toward control values, with no significant differences among groups.

\section{Action-potential Duration}

Neither heptanol, glybenclamide, nor BDM had a significant effect on action-potential duration to $50 \%$ repolariza- 


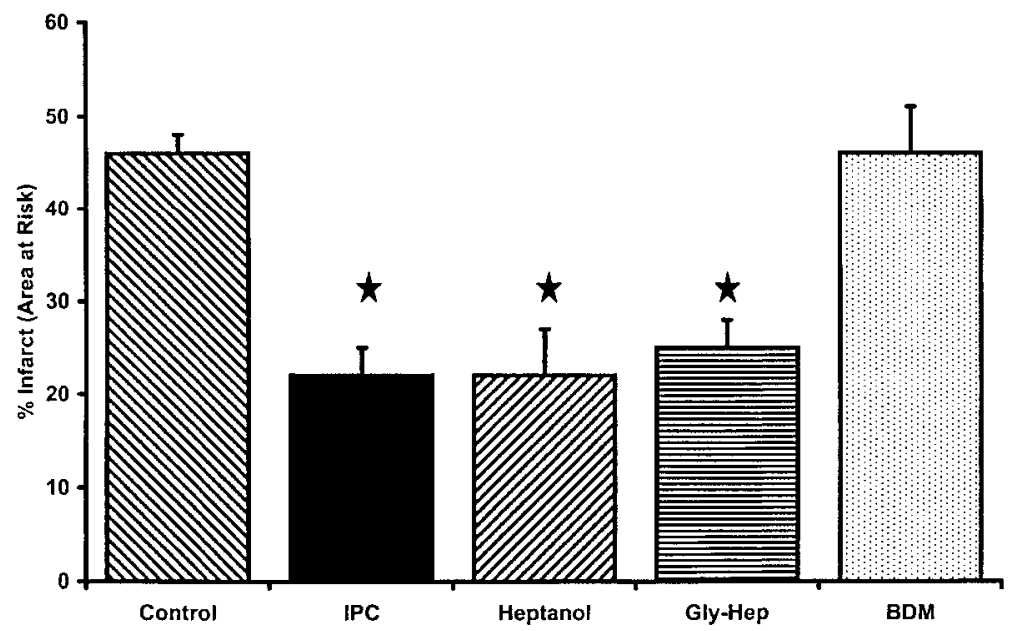

Figure 3. Changes in infarct size expressed as a percentage of the area at risk. Data are given as mean \pm SEM. Gly-Hep, $10 \mu \mathrm{mol} / \mathrm{L}$ Glybenclamide plus $1 \mathrm{mmol} / \mathrm{L}$ heptanol. Open triangles indicate a $P$ value of less than .05 compared with control.

TABLE 1. Weights of the left ventricle, area at risk, infarct area, and infarct size for all experiment groups

\begin{tabular}{lcccc}
\hline & LV weight $(\mathbf{g})$ & Area at risk $(\mathbf{g})$ & Infarct area $(\mathbf{g})$ & Infarct size $(\%)$ \\
\hline Control & $3.34 \pm 0.19$ & $2.50 \pm 0.29$ & $1.17 \pm 0.15$ & $46 \pm 2$ \\
IPC & $3.13 \pm 0.19$ & $2.11 \pm 0.14$ & $0.46 \pm 0.08$ & $22 \pm 3^{*}$ \\
Heptanol & $3.53 \pm 0.12$ & $2.46 \pm 0.40$ & $0.52 \pm 0.11$ & $22 \pm 5^{*}$ \\
Gly-Hep & $3.58 \pm 0.12$ & $2.15 \pm 0.14$ & $0.66 \pm 0.11$ & $25 \pm 3^{*}$ \\
BDM & $3.48 \pm 0.14$ & $2.49 \pm 0.25$ & $1.17 \pm 0.16$ & $46 \pm 5$ \\
\hline
\end{tabular}

Data are given as mean \pm SEM.

$L V$, Left ventricular; Gly, $10 \mu \mathrm{mol} / \mathrm{L}$ glybenclamide; Hep(tanol), $1 \mathrm{mmol} / \mathrm{L}$ heptanol.

${ }^{*} P<.05$ with respect to control.

tion $\left(\mathrm{APD}_{50}\right)$. During pretreatment, transient ischemia significantly reduced $\mathrm{APD}_{50}$, but during regional ischemia, there were no significant differences among groups. During reperfusion, $\mathrm{APD}_{50}$ was shorter in $\mathrm{BDM}$ hearts, but the differences did not reach significance.

\section{Coronary Flow}

Heptanol pretreatment tended to increase coronary flow, and this change was not attenuated by prior infusion of glybenclamide. All hearts showed a significant decrease in coronary flow during regional ischemia and a significant return to control during reperfusion; there were no significant differences among groups.

\section{Infarct Size}

There were no significant differences in area at risk, left ventricular weight, and risk area weight among groups (Table 1). A comparison of infarct sizes is shown in Figure 3. Control hearts had an infarct size of $46 \% \pm 2 \%$. IPC significantly reduced infarct size to $22 \% \pm 3 \%(P<.01)$.
Hearts exposed to heptanol before regional ischemia also showed a significant decrease in infarct size $(22 \% \pm 5 \%$, $P<.01)$. Infusion of glybenclamide before heptanol did not significantly change infarct size $(25 \% \pm 3 \%, P=$ not significant compared with heptanol alone), whereas pure electromechanical uncoupling with BDM did not precondition $(46 \% \pm 5 \%, P=$ not significant).

\section{Discussion}

Preconditioning has been described as a possible mechanism for myocardial protection. Since the original report by Murry and associates, ${ }^{1}$ many investigators have confirmed that IPC reduces ventricular infarct size after prolonged ischemia. However, as shown in several studies, IPC is not benign: It increases end-diastolic pressure, and therefore even a brief period of ischemia should be avoided if possible. This has caused investigators to search for a mechanism of preconditioning that does not harm the ventricle. To date, many different stimuli have been found to provoke a preconditioning response, including $\alpha$-adrenergic agonists, ${ }^{6,7}$ 
activators of protein kinase $\mathrm{C}, 6,8$ adenosine, ${ }^{6,8}$ and ATPsensitive potassium channel openers. ${ }^{9,10}$

Pharmacologic preconditioning offers many potential advantages over IPC. Mechanical damage to the coronary artery from local ischemic maneuvers can be avoided. Agents can be infused, in some cases, directly into the blood stream. Pharmacologic agents can be reversed or are metabolized away quickly. The dosages can be precisely controlled and individualized.

Despite these many stimuli, no comprehensive mechanism of action has yet been described for preconditioning, either ischemic or pharmacologic. Our data suggest for the first time that gap junction uncoupling preconditions the heart and that this protection is conferred independent of either $\mathrm{K}^{+}{ }_{\text {ATP }}$ channel activation or acute depression of mechanical performance.

\section{Clinical Applications}

An important application for preconditioning lies in protecting the arrested heart during complex operations. The currently popular myoprotective strategy of intermittently infusing cold potassium-rich crystalloid or sanguine cardioplegia results in significant mechanical and electrical derangements in the early postoperative period. Many researchers have already tried to add the beneficial effects of pharmacologic preconditioning to potassium cardioplegia, but the results have been mixed. ${ }^{15,16}$ Although these experiments were not carried out in an arrested heart, it is reasonable to expect that pretreatment with a gap junction uncoupler will improve postcardioplegic recovery.

\section{Role of Gap Junctions in Preconditioning}

In 1991, Murry and coworkeres ${ }^{17}$ found that AA was liberated during transient ischemia. Since then, investigators have shown that AA uncouples isolated ventricular myocyte pairs ${ }^{4}$ and that octanol, a gap junction uncoupler, protects the brain from ischemia. ${ }^{18}$ With regard to the heart, heptanol has been shown to limit myocardial infarct size when infused after ischemia and during reperfusion. ${ }^{19}$ Although consistent with these other studies, we have shown for the first time that the infusion of heptanol before ischemia protects the heart from prolonged regional ischemia.

The mechanism by which preconditioning in general reduces infarct size remains an object of intense investigation. It is quite likely, however, that cell-to-cell communication plays an important role in this process because secondary messengers travel across gap junctions and transmit death messengers. The mechanism underlying heptanol's protective effect remains unclear because it has been shown that recovery of coupling is quite rapid once the heptanol is washed out (ie, on the order of 90 to 120 seconds). Therefore it is more likely that brief cellular uncoupling serves more as a trigger event than a mechanism: A cell is better able to uncouple itself from its sick neighbors after a pretreatment than it is without such a stimulus.

\section{Role of the $\mathrm{K}^{+}{ }_{\text {ATP }}$ Channel}

It appears that many of the drugs proved effective at pharmacologic preconditioning exert their effect by activating the $\mathrm{K}^{+}{ }_{\text {ATP }}$ channel. By treating the heart with glybenclamide to block $\mathrm{K}^{+}{ }_{\text {ATP }}$ channels before heptanol infusion, we were able to determine that the $\mathrm{K}^{+}{ }_{\text {ATP }}$ channel does not participate in heptanol's preconditioning mechanism. We chose a 5-minute glybenclamide infusion before heptanol preconditioning because we have shown in other studies that this sufficiently blocks the protective effects of the $\mathrm{K}^{+}{ }_{\text {ATP }}$ channel opener pinacidil..20,21

\section{Study Limitations}

We studied rabbit hearts in a nonworking, isolated crystalloid-perfused model. The drawbacks of this model include, but are not limited to, differences in energetics and performance between working and nonworking models, as well as problems with an asanguinous perfusate. Although a more perfect reflection of the clinical state might have been achieved with an in situ, blood-perfused, working heart model, data collection, model manipulation, and drug delivery would have proved far more difficult.

We also chose to study global ventricular function rather than regional function, as reflected by endocavitary pressure development. To study regional function in such a small heart as the rabbit's, the state of the art would require direct instrumentation with ultrasonographic equipment, damaging the myocardium. We do not believe that this is a significant limitation, however, because our developed pressure changes were quite pronounced and easily tabulated.

Finally, there has been some controversy surrounding the time allowed for reperfusion. In this study we used 120 minutes of reperfusion, which clearly yielded a discernable infarct size, as measured with triphenyl tetrazolium chloride. Although investigators have used reperfusion times varying from 60 to 180 minutes, ${ }^{22-27}$ we demonstrated, in a separate set of experiments, that hearts subjected to 180 minutes of reperfusion exhibited a similar infarct size to those reperfused for 120 minutes. ${ }^{26}$

\section{Conclusion}

Pretreatment of the heart with the gap junction uncoupler heptanol protects the heart against prolonged regional ischemia. This mechanism is independent of both the $\mathrm{K}^{+}{ }_{\text {ATP }}$ channel and electromechanical depression.

\section{References}

1. Murry CE, Jennings RB, Reimer KA. Preconditioning with ischemia: a delay of lethal cell injury in ischemic myocardium. Circulation. 1986;74:1124-36. 
2. Starkopf J, Andreasen TV, Bugge E, Ytrehus K. Lipid peroxidation arachidonic acid and products of lipoxygenase pathway in ischemic preconditioning of rat heart. Cardiovasc Res. 1998;37:66-75.

3. Massey KD, Minnich BN, Burt JM. Arachidonic acid and lipoxygenase metabolites uncouple neonatal rat cardiac myocyte pairs. Am J Physiol. 1992;263:C494-501.

4. Schmilinsky-Fluri G, Valiunas V, Willi M, Weingart R. Modulation of cardiac gap junctions: the mode of action of arachidonic acid. $\mathrm{J} \mathrm{Mol}$ Cell Cardiol. 1997;29:1703-13.

5. Burns PG, Krukenkamp IB, Caldarone CA, Gaudette GR, Bukhari EA, Levitsky S. Does cardiopulmonary bypass alone elicit myoprotective preconditioning? Circulation. 1995;92:II447-51.

6. $\mathrm{Hu}$ K, Duan D, Li GR. Protein kinase C activates ATP-sensitive potassium current in human and rabbit ventricular myocytes. Circ Res. 1996;78:492-8.

7. Banerjee A, Locke-Winter C, Rogers IKB, Michell MB, Bre EC, Cairns CB, et al. Preconditioning against myocardial dysfunction after ischemia and reperfusion by an alpha1 adrenergic mechanism. Circ Res. 1993;73:656-70.

8. Khandoudi N, Moffat MP, Karmazyn M. Adenosine-sensitive alpha 1-adrenoceptor effects on reperfused ischaemic hearts: comparison with phorbol ester. Br J Pharmacol. 1994;112:1007-16.

9. Yao Z, Gross GJ. Role of nitric oxide, muscarinic receptors, and the ATP-sensitive $\mathrm{K}+$ channel in mediating the effects of acetylcholine to mimic preconditioning in dogs. Circ Res. 1993;73:1193-201.

10. Parrat JR, Kane KA. KATP channels in ischemic preconditioning. Cardiovasc Res. 1994;28:783-7.

11. Gasser R, Klein W, Kickenweiz E. Vasodilative response to hypoxia and simulated ischemia is mediated by ATP-sensitive $\mathrm{K}+$ channels in guinea pig thoracic aorta. Angiology. 1993;44:228-43.

12. Bijlstra PJ, den Arend JA, Lutterman JA, Russel FG, Thien T, Smits P. Blockade of vascular ATP-sensitive potassium channels reduces the vasodilator response to ischaemia in humans. Diabetologia. 1996;39: 1562-8.

13. Sgard F, Faure C, Drieu la Rochelle C, Graham D, O'Connor SE, Janiak P, et al. Regulation of ATP-sensitive potassium channel mRNA expression in rat kidney following ischemic injury. Biochem Biophys Res Commun. 2000;269:618-22.

14. Li T, Sperelakis N, Teneick RE, Solaro RJ. Effects of diacetyl monoxime on cardiac excitation-contraction coupling. J Pharmacol Exp Ther. 1985;232:688-95.

15. Illes RW, Wright K, McBride KI, Yand CJ, Tristan A. Ischemic preconditioning improves preservation with crystalloid cardioplegia. Ann Thorac Surg. 1994;58:1481-5.
16. Kaukoranta PK, Lepojarvi MP, Ylitalo KV, Kiviluoma KT, Peuhkurinen KJ. Normothermic retrograde blood cardioplegia with or without preceding ischemic preconditioning. [see comments]. Ann Thorac Surg. 1997;63:1268-74.

17. Murray CE, Richar VJ, Jennings RB, Reimer KA. Myocardial protection is lost before contractile function recovers from ischemic preconditioning. Am J Physiol Heart Circ Physiol. 1991;260:H796804.

18. Rawanduzy A, Hansen A, Hansen TW, Nedergaard M. Effective reduction of infarct volume by gap junction blockade in a rodent model of stroke. J Neurosurg. 1997;87:916-20.

19. Garcia-Dorado D, Inserte J, Ruiz-Meana M, Gonzalez MA, Solares J, Julia M, et al. Gap junction uncoupler heptanol prevents cell to cell progression of hypercontracture and limits necrosis during myocardial reperfusion. Circulation. 1997;96:3579-86.

20. Saltman AE, Krukenkamp IB, Gaudette GR, Levitsky S. Pharmacologic preconditioning with pinacidil provides superior electrophysiological and mechanical preservation for the heart undergoing minimally invasive revascularization. Surg Forum. 1996;47:295-7.

21. Saltman AE, Krukenkamp IB, Gaudette GR, Horimoto H, Levitsky S. Pharmacological preconditioning with the adenosine triphosphatesensitive potassium channel opener pinacidil. [see comments]. Ann Thorac Surg. 2000;70:595-601.

22. Birnbaum Y, Hale SL, Kloner RA. Differences in reperfusion length following 30 minutes of ischemia in the rabbit influence infarct size, as measured by triphenyltetrazolium chloride staining. J Mol Cell Cardiol. 1997;29:657-66.

23. Horimoto H, Saltman AE, Gaudette GR, Krukenkamp IB. Nitric oxide-generating beta-adrenergic blocker nipradilol preserves postischemic cardiac function. Ann Thorac Surg. 1999;68:844-9.

24. Sandhu R, Diaz RJ, Mao GD, Wilson GJ. Ischemic preconditioning: differences in protection and susceptibility to blockade with singlecycle versus multicycle transient ischemia. Circulation. 1997;96:984-95.

25. Schulz R, Rose J, Heusch G. Involvement of activation of ATPdependent potassium channels in ischemic preconditioning in swine. Am J Physiol Heart Circ Physiol. 1994;267:H1341-52.

26. Burns PG, Krukenkamp IB, Caldarone CA, Gaudette GR, Levitsky S. Is the preconditioning response conserved in senescent myocardium? Ann Thorac Surg. 1996;61:925-9.

27. Kersten JR, Schmeling TJ, Pagel PS, Gross GJ, Warltier DC. Isoflurane mimics ischemic preconditioning via activation of $\mathrm{K}(\mathrm{ATP})$ channels: reduction of myocardial infarct size with an acute memory phase. Anesthesiology. 1997;87:361-70. 